ENCYCLOPEDEE Encyclopédie berbère

BERBERE

$11 \mid 1992$

11 | Bracelets - Caprarienses

\title{
Calama (Kalama)
}

G. Souville

\section{OpenEdition}

Journals

Édition électronique

URL : http://journals.openedition.org/encyclopedieberbere/1902

DOI : 10.4000/encyclopedieberbere.1902

ISSN : 2262-7197

\section{Éditeur}

Peeters Publishers

\section{Édition imprimée}

Date de publication : 1 septembre 1992

Pagination : 1707-1709

ISBN : 2-85744-581-4

ISSN : 1015-7344

\section{Référence électronique}

G. Souville, «Calama (Kalama) », Encyclopédie berbère [En ligne], 11 | 1992, document C9, mis en ligne le 01 avril 2013, consulté le 25 septembre 2020. URL : http://journals.openedition.org/ encyclopedieberbere/1902; DOI : https://doi.org/10.4000/encyclopedieberbere.1902

Ce document a été généré automatiquement le 25 septembre 2020

(C) Tous droits réservés 


\section{Calama (Kalama)}

\section{G. Souville}

1 La ville antique occupait l'emplacement de l'actuelle ville de Guelma et s'étendait plus au nord-est, au pied du massif de la Mahouna dominant la vallée de la Seybouse, à 74 km d'Hippo Regius.

2 Avec Orose $(\mathrm{V}, 15,6)$ on a essayé de l'identifier à la ville de Suthul mentionnée par Salluste (Bellum Jugurthinum, 37) ; c'est probablement près de Calama qu'eut lieu la victoire de Jugurtha sur les Romains commandés par A. Postumius.

3 La ville était peut-être d'origine phénicienne ; l'influence punique y fut durable comme le montre la présence de nombreuses stèles; encore à l'époque romaine les magistrats annuels de la cité portaient le titre punique de sufète ; un princeps siégeait à leurs côtés sans que ses attributions soient bien connues; il s'agit peut-être d'un chef de tribu indigène associée à la cité, mais on pense plutôt au premier personnage de l'assemblée municipale.

4 Rattachée à la Proconsulaire, Calama était sans doute municipe sous Trajan, les habitants ayant été inscrits dans la tribu Papiria, celle de cet Empereur. Elle n'est mentionnée ni dans Ptolémée, ni dans l'Itinéraire antonin ou la Table de Peutinger. Encore municipe sous Septime Sévère, elle est qualifiée de colonie dans de nombreuses inscriptions des $\mathrm{III}^{\mathrm{e}}$ et $\mathrm{IV}^{\mathrm{e}}$ siècles. Après avoir été placée en Numidie, elle fut sous l'autorité du Proconsul d'Afrique au temps de Dioclétien.

5 Une communauté chrétienne s'y trouvait déjà lors de la persécution de Dioclétien. Comme ailleurs Catholiques et Donatistes s'y opposèrent. Plusieurs évêques de Calama sont connus; le plus célèbre d'entre eux est Posidius qui eut d'ailleurs à lutter contre les Donatistes. Contemporain et ami de saint Augustin, il fut aussi son biographe et son bibliographe (Mandouze A., Prosopographie de l'Afrique chrétienne (303-533), Paris, 1982, p. 890-896, 1254 et passim).

6 Calama tomba au pouvoir de Genseric en 437, fut restaurée par le comte Paulus agissant sur les ordres du patrice Solomon. Elle devint alors une des villes forteresses de la Numidie byzantine puis entra en décadence. Mentionnée encore au XII siècle, elle se 
réduisait à un petit groupe d'habitations lors de la conquête française (1836), avec des ruines de monuments encore conséquentes.

7 Il est difficile de reconstituer le plan et l'aspect général de la ville. Les seuls monuments importants sont le théâtre et les thermes. Le.théâtre fut élevé grâce à la générosité d'une fiaminique Annia Aelia Restituta au $\mathrm{III}^{\mathrm{e}}$ siècle ap. J.-C.; il fut restauré et pratiquement reconstruit de 1902 à 1918 ; il mesurait 58,05 m de large. La construction était faite en blocage avec revêtements de pierres de petit appareil ; les gradins avaient presque tous disparu; ils devaient être au nombre de dix dans la zone inférieure et de douze dans la seconde zone. L'orchestre était pavé de marbre; derrière la scène, flanquée de deux salles rectangulaires, un portique à colonnes formait façade. L'existence d'un Forum nouum n'est connue que par une inscription. Il y avait également des restes d'arcades, un édicule consacré à Neptune, des citernes et une église chrétienne hors de la ville.

Stèle de tradition libyco-punique. Musée de Guelma. Photo G. Camps.

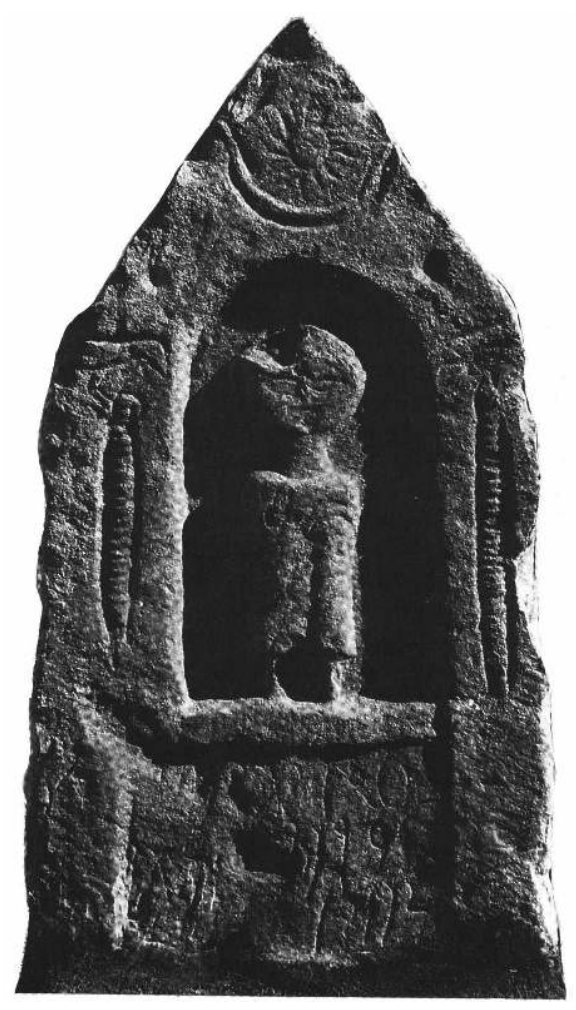

Les thermes construits en blocage avec revêtements de pierres de petit appareil et en briques peuvent remonter au $\mathrm{II}^{\mathrm{e}}$ siècle ap. J.-C. Ils furent inclus dans la forteresse byzantine. Celle-ci fut sans doute édifiée sur une enceinte antérieure; elle était défendue par treize tours et mesurait $278 \mathrm{~m}$ de long sur 219 de large.

En 1953 fut découvert un trésor de 7499 pièces provenant presque toutes de l'atelier de Rome; les plus récentes datent du début de 257 ; il fut sans doute enfoui à la suite de troubles locaux (Turcan R., Le trésor de Guelma. Étude historique et monétaire, Paris, 1963, 158 p., 18 pl.). 
Stèle néo-punique de Calama. Photo G. Camps.

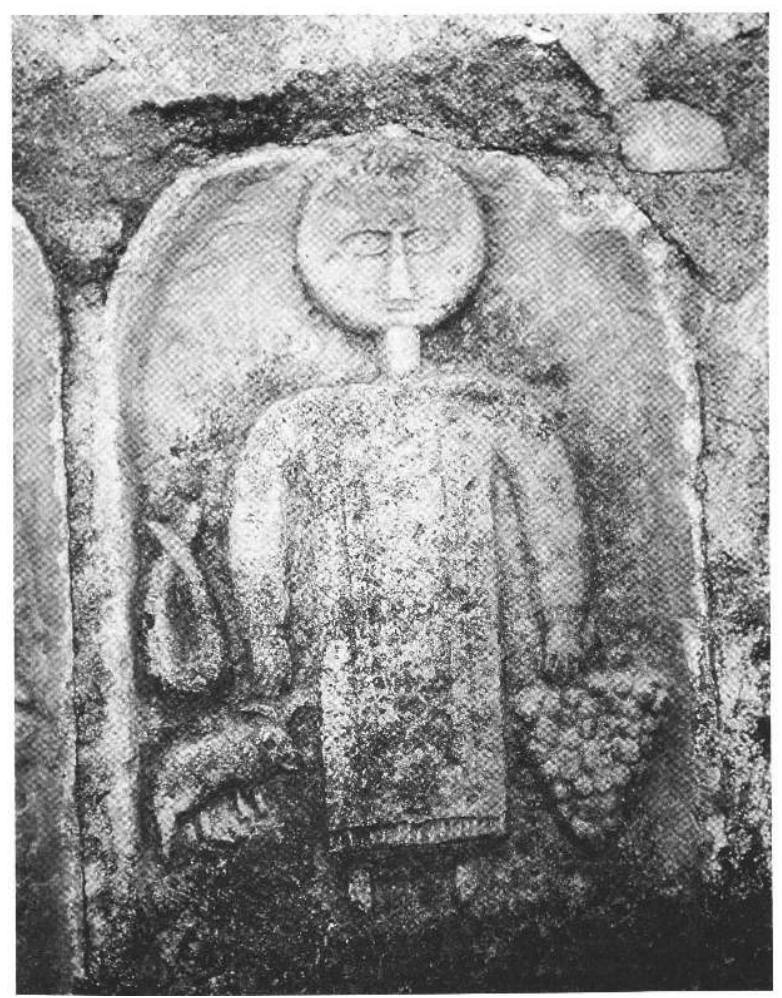

10 La plupart des objets antiques recueillis à Calama et dans la région sont conservés au musée de Guelma (Pachtère F.-G. de, Musée de Guelma, Paris, 1909, 62 p., 10 pl.).

\section{BIBLIOGRAPHIE}

GSELL S., Atlas archéologique de l'Algérie, Paris, 1904, feuille n 9, Bône, nº 146.

Id., Inscriptions latines de l'Algérie, Paris, 1922, t. 1, p. 20-48.

SOUVILLE G., « Calama (Guelma) », The Princeton Encyclopedia of classical sites, Princeton, 1976, p. 184-185.

INDEX

Mots-clés : Algérie, Antiquité, Villes 